\title{
A study to Assess the Effect of Individual Structured Teaching Programme on Knowledge regarding Management of Diabetes Mellitus among patient with Diabetes Mellitus at selected Hospital
}

\author{
Mrs. S. Andal M.Sc (N) ${ }^{1}$ \\ ${ }^{1}$ Associate Prof., Faculty of Nursing, Rama University, \\ Kanpur., Uttar Pradesh, India
}

\begin{abstract}
:
A study to assess the effect of individual Structure Teaching Programme on knowledge regarding management of diabetes mellitus among patient with diabetes mellitus at selected hospitals with the objective to assess the pre-test knowledge regarding management of diabetes mellitus, to assess the effect of individual structure teaching programme and to associate the level of knowledge with selected demographic variables on management of diabetes mellitus. The hypothesis of this study was no significant difference in level of knowledge on management of diabetes mellitus among patients with diabetes mellitus. A quantitative approach, preexperimental research with one group pre-test posttest design was used in this study. A purposive sampling technique was used to select 100 samples and the structure questionnaire was used as a tool for collecting data. The major finding of the study reveal that majority of patients in post test $63(63 \%)$ had adequate knowledge, 25 (25\%) had moderate knowledge and $12(12 \%)$ had inadequate knowledge. The mean and standard deviation value of individual structure teaching programme pre-test Mean 7.13, SD 2.11 and post-test Mean 15.02, SD 2.35. In the present study it was found that the effect of individual structure teaching programme on management of diabetes mellitus was assessed by paired $t$ test.the value of $t$ is 15.41 at the level of $t$ $=0.05$ level which is higher than the table value $t=$ 2.05 which show highly significance.Thus the HO (null) hypothesis was accepted.
\end{abstract}

$\begin{array}{llcc}\text { Keywords: } & \text { Individual } & \text { Structured } & \text { Teaching } \\ \text { Programme, } & \text { Knowledge, } & \text { Management, } & \text { Diabetes } \\ \text { Mellitus } & \end{array}$

\section{Introduction}

Health is a state of well being of an individual. It is said that to be healthy, individual should be free from disease. Disease is the major aspect to make an individual unhealthy. It is the field of science, disease are mainly classified into two major group they are communicable disease and noncommunicable disease. Most of the communicable diseases are infectious hence they can be called as infectious disease.

Diabetes is a chronic disease that occurs when the pancreas does not produce enough insulin, or alternatively, when the body cannot effectively use the insulin it produces. People with impaired glucose tolerance or impaired fasting glucose are at high risk of progressing to type 2 diabetes, although this is not inevitable.

Type 1 diabetes is characterized by a lack of insulin production in the body .type 2 diabetes results from the body's ineffective use of insulin type 2 diabetes comprises $90 \%$ of people with diabetes around the world, and is largely the result of excess body weight and physical inactivity. This type of diabetes was seen only in adults but it is now also occurring in obese children.

Diabetes is one of the most frequently occurring diseases in the world affecting nearly 2 to $4 \%$ of the population (World Health Organization, 1998). Research studies have shown that the progress of diabetes is also associated with a high risk of developing vascular, renal, retinal and neuropathy complication leading to premature disability and death. To prevent type 2 diabetes and its complication, people should achieve and maintain healthy body weight, be physically active- at least 30 minutes of regular moderate -intensity activity on 
most days. More activity is required for weight control.

\section{Need for the study}

India is one of the epicenters of the global diabetes mellitus pandemic. Rapid socioeconomic development and demographic changes, along with increased susceptibility for Indian individuals, have led to the explosive increase in the prevalence of diabetes mellitus in India over the past four decades. Type 2 diabetes mellitus in Asian Indian people is characterized by a young age of onset and occurrence at low levels of BMI. Available data also suggest that the susceptibility of Asian Indian people to the complications of diabetes mellitus differs from that of white populations.

Management of this disease in India faces multiple challenges, such as low levels of awareness, paucity of trained medical and paramedical staff and un affordability of medications and services. Novel interventions using readily available resources and technology promise to revolutionize the care of patients with diabetes mellitus in India. As many of these challenges are common to most developing countries of the world, the lessons learnt from India's experience with diabetes mellitus are likely to be of immense global relevance. In this Review, we discuss the epidemiology of diabetes mellitus and its complications in India and outline the advances made in the country to ensure adequate care. We make specific references to novel, cost-effective interventions, which might be of relevance to other low-income and Middle East countries.

\section{Objectives}

- To assess the pre -test knowledge regarding management of diabetes mellitus.

- To assess the effect of individual structure teaching programmed on knowledge regarding management of diabetes mellitus.

- To associate the level of knowledge with selected demographic variables on management of diabetes mellitus.

\section{Hypothesis}

H0: There is no significant difference in level of knowledge on management of diabetes mellitus among patients with diabetes mellitus

\section{Research Methodology}

Research Approach:

The research approach for the study was quantitative approach.

\section{Research Design:}

The research design adopted for this study is pre experimental research with one group pre- test post-test design.

\section{Variables}

Independent Variable:- In this study the independent variable is Individual Structured Teaching Programme
Dependent Variable:- In this study the dependent variable is knowledge of patients about management of diabetes mellitus

\section{Population}

The population under study is those who admitted in medical ward at selected hospital.

Sample:-

The present study was conducted among the patients who are admitted in medical ward at district hospital durg.

\section{Sampling Technique}

A purposive sampling technique was used to select the sample.

\section{Sample Size}

100 patients those who are admitted in medical ward during the study period.

\section{Sample Criteria}

Inclusion Criteria

1) Patient who can understand and write hindi.

2) Those who are willing to participate in the study.

Description of Tool:-

A structure questionnaire will be developed as a tool for data collection. It will consist of the following section.

Section-A:-

It includes the demographic data such as age, gender, religion, residential area, types of family, family monthly income, dietary pattern and education level.

Section B:-

Including 20 multiple choice questions related to management of diabetes mellitus.

Scoring:- The questionnaire contains 20 each multiple choice questions. Each correct answer carries 1 mark and each wrong answer carries 0 mark.

\section{Grading the Basis of Marks:-}

\begin{tabular}{|c|l|c|l|}
\hline S.NO. & MARKS & PERCENTAGE & LEVEL \\
\hline 1. & $1-10$ & $<50$ & $\begin{array}{l}\text { Inadequate } \\
\text { knowledge }\end{array}$ \\
\hline 2. & $11-15$ & $50-75$ & $\begin{array}{l}\text { Moderately } \\
\text { Adequate } \\
\text { Knowledge }\end{array}$ \\
\hline 3. & $16-20$ & $>75$ & $\begin{array}{l}\text { Adequate } \\
\text { Knowledge }\end{array}$ \\
\hline
\end{tabular}

\section{Data Analysis and Interpretation}

Section-I: Analysis of pre-test and post test knowledge regarding management of diabetes mellitus.

Section-II: Evaluation of the effectiveness of STP on knowledge regarding management of diabetes mellitus. 
Section-III: Association of the pre-test knowledge level of diabetes mellitus with demographic variables.

\section{Section-I : Analysis of Knowledge Regarding}

Management of Diabetes Mellitus.

Table No. 1 -Pre-Test and Post-Test

Knowledge Score $\mathrm{n}=100$

\begin{tabular}{|c|c|c|c|}
\hline Test & Inadequate & $\begin{array}{c}\text { Moderately } \\
\text { Adequate }\end{array}$ & Adequate \\
\hline Pretest & $48(48 \%)$ & $38(38 \%)$ & $14(14 \%)$ \\
\hline Posttest & $12(12 \%)$ & $25(25 \%)$ & $63(63 \%)$ \\
\hline
\end{tabular}

Above table indicates that pre-test and posttest knowledge level of the samples. In pre-test out of 100 samples 48 (48\%) having inadequate knowledge, 38 (38\%) having moderately adequate knowledge and 14 (14\%) member having adequate knowledge. In post-test out of 100 samples 12 (12\%) having inadequate knowledge, 25 (25\%) having moderate adequate knowledge and $63(63 \%)$ member having adequate knowledge.

Fig 01: Bar Diagram showing Level of Knowledge on Management of Diabetes Mellitus

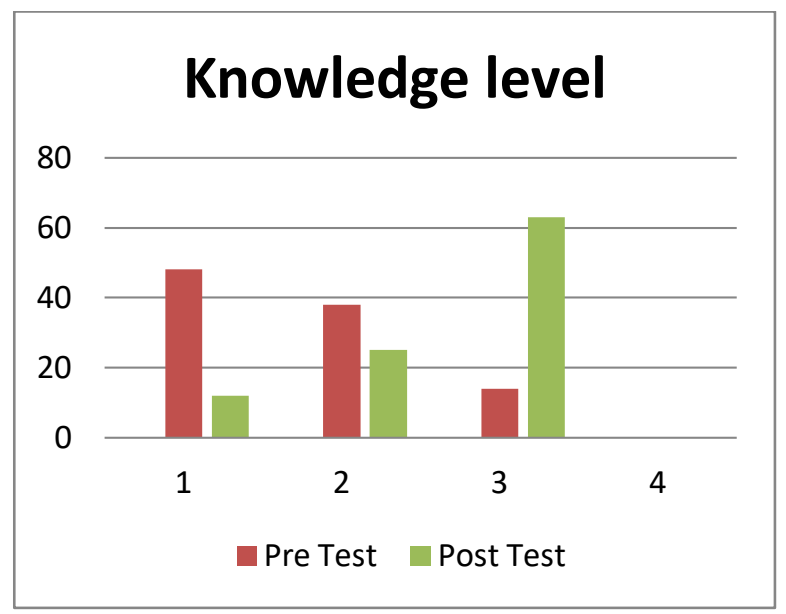

Table No.2: Mean and Standard Deviation Value of Pre-Test and Post-Test of Knowledge

\begin{tabular}{|l|c|c|}
\hline & Mean & SD \\
\hline Pre-test & 7.13 & 2.11 \\
\hline Post-test & 15.03 & 2.35 \\
\hline
\end{tabular}

Above table shows that the mean and standard deviation value of individual structure teaching programme pre-test mean 7.13 , standard deviation 2.11 and post-test mean 15.02 and standard deviation 2.35 .

Section -II: Evaluation of the Effectiveness of STP on Knowledge regarding Management of Diabetes Mellitus

Table No- 3: Effectiveness of Structure Teaching Programme on Knowledge regarding Management of Diabetes Mellitus

\begin{tabular}{|l|l|}
\hline Paired t Value & Significance \\
\hline 15.41 & $\mathbf{P}=\mathbf{0 . 0 5}$ H.S \\
\hline
\end{tabular}

Section III: Association between Pre-Test Level of Knowledge \& Demographic Variables on Management of Diabetes Mellitus

The level of association between pre test knowledge and theDemographic variable of the sample where none of the demographic variable such as age, gender, religion, area of living, types of family, family monthly income, food habits and educational level and previous knowledge are showing non significance at $\mathrm{p}>0.05$.

The level of association between post- test knowledge and the Demographic variable of the sample where none of the demographic variable such as age, gender, religion, area of living, types of family, family monthly income, food habit, educational level and previous knowledge are showing non significance at $\mathrm{p}>0.05$.

\section{Implementation}

In this context, the health professionals, especially the nurse have a major role in providing information about management of diabetes mellitus, which is one of the most cost effective weapons to reduce morbidity and mortality due to disease.

\section{Nursing Practice}

Nursing is an art and a science. As a science, nursing is based upon a knowledge that is always changing with new discoveries and innovation. When nurses integrate the science and art of nursing into their practice, the quality of care provided to client is at a level of excellence that benefits clients in innumerable ways.

The finding of the present study emphasize the management of diabetes mellitus Which can put in to nursing practice in early identification of diabetes 
mellitus and a planned teaching programme can be used as a basis for educating them in prevention of this problem.

\section{Nursing Education}

This study helps the nursing students to improve the knowledge about management of diabetes mellitus. As outreach programme is a part of nursing curriculum, students can conduct of preexperimental study to assess the effects of individual structure teaching programme on knowledge regarding management of diabetes mellitus.

\section{Nursing Administration}

As a nursing administrator much can be done at grass route level to improve knowledge of management of diabetes mellitus. Nurse as a administrator has a role in planning the policies for imparting health information to the target population.

\section{Nursing Research}

The research findings may be beneficial to the students researchers and others to carryout there research work. The methods used for the study can follow by the students for their investigation, analysis and interpretation.

\section{Conclusion}

The study concludes that Individual Teaching Programme was on knowledge regarding management of diabetes mellitus was shows effective among patients with Diabetes mellitus. It also concludes the teaching was effective in gaining the knowledge.

\section{References}

[1] Mani Mrinalini, Chintamani. Lewis's Medical surgical nursing .2nd edition. vol-II. barakhamba, new Delhi ;2015, RELX India private limited; $p$. 1676-1680.

[2] Ahuja, M.S., Chandalia, B.H., Shah, N.S.\& Joshi, R.S., (2002).Text book of Diabetes Mellitus. Hyderabad: Mudrika.

[3] AristidisVeves., John M. Girurini.\&Frank W. Logerfo(2002). The diabetic foot Medical Surgical management. New Jersey: Humana press.

[4] Black,J.M. \&Hawks ,J.K.,(2005). Medical Surgical Nursing: Clinical management for positive outcomes. St.Louis : Saunders.

[5] Davidson. (2006). Principles \& Practice of Medicine. Philadelphia, Churchill Livingstone.

[6] Denise, F. Polit., \& Cheryl Tatano Beck. (2008).Nursing Research: Generating and assessing Evidence for Nursing Practice. Philadelphia, Lippincott Williams \& Wilkins.

[7] Kumar, \& Clark. (2006). Clinical Medicine. Philadelphia, Elsevier Saunders.

[8] Smeltzer C. Suzanne, \& Bare G. Brenda. (2005).Textbook of Medical Surgical Nursing. Philadelphia, Lippincott Williams \& Wilkins. 